\title{
The Life and Intellectual Transformation of the Late Qing Official Scholar Yun Yu-Ding (1862-1917)
}

\author{
Liu Xunqian and Yang Yi
}

\begin{abstract}
This paper discusses the experiences in learning and the changes in thought of Yun Yuding (1862-1917), an official-scholar during the late Qing Dynasty. Using Yun's Chengzhai Diary as a primary source, it first reconstructs his biography along with his scholarly associations. As Qian-Jia textual-critical research was the dominant school in the academic community in the Qing dynasty, Yun was deeply influenced by evidential study in Yanghu (modern-day Jiangsu) However, there was another important trend of thought in Beijing, advocated by high-ranking officials such as Xu Tong (1819-1900) and Sun Jianai (1827-1909), which cherished moral cultivation. This paper discovers that Yun worked under Xu Tong in the imperial Hanlin Academy (Hanlin Yuan) in Beijing after he obtained his jinshi (the highest degree in imperial times) in 1889. He increasingly found that he needed to closely engage with Xu's academic preference if he was to gain any recognition. Yun finally became an advocate of merging the learning of the schools of Zhu Xi (1130-1200) and Wang Yangming (1472-1529) He agreed most with the academic stance of $\mathrm{Gu}$ Xiancheng $(1550-1612)$ because of his involvement in political affairs. The paper also finds that some of Yun's ideas suggest that Yun might have absorbed Liang Qichao's (1873-1929) idea into his thinking. In general, the fall of evidential study in the late Qing period had the effect of what Thomas Kuhn terms a paradigm shift. In this context, this paper contributes a case study to explain why the Chinese literati converted to Neo-Confucianism.
\end{abstract}

Index Terms-History of Qing scholarship, intellectual resources, Late Qing China, Yun Yu-Ding (1862-1917).

\section{INTRODUCTION}

Historians regard the Qing dynasty (1644-1911) as a relatively well-studied and understood period because of the rich archival and non-archival sources that have survived; but our knowledge of Qing intellectual history is far from adequate. In particular, we know very little about the academic preferences and thoughts of the Qing official elite ${ }^{1}$, despite the abundant material and written evidence that they left behind. As this paper shows, the study of an official scholar's diary provides a new entry point into the intellectual world, the academic preferences, and the cultural values of the upper class at the end of the Late Qing dynasty.

Yun Yu-Ding 恽毓鼎 (1862-1917) was a Chinese Confucian scholar and imperial tutor who lived during the Late Qing dynasty. In 1889, he obtained the position of jinshi

Manuscript received April1, 2016; revised June 1, 2016.

The authors are with The University of Hong Kong, Pokfulam, Hong Kong (e-mail: 1xunqian@hku.hk,u3002811@hku.hk).

${ }^{1}$ In this paper official elite is defined as those people who were recruited in the bureaucracy and assumed leadership roles in state and social affairs. They were distinguished from people of low or non-literati status, who did not enjoy a long history of official careers in their families.
进士 (the highest degree available in imperial times) in his civil service examinations and was subsequently admitted to the prestigious Hanlin Academy 翰林院. After the 1911 Revolution, Yun recognised himself as a loyalist of the fallen dynasty. He passed away in Beijing in 1918.

Judging from his life experiences, Yun can be recognised as a typical member of the official elite and a typical official scholar selected by the imperial examination system in the Late Qing dynasty [1]. Using Yun's Cheng Zhai Diary 澄斋 日记as a primary source and paying close attention to the historical context, this paper reconstructs his biography along with his scholarly associations, then focuses on Yun's learning experiences and his changes in thought.

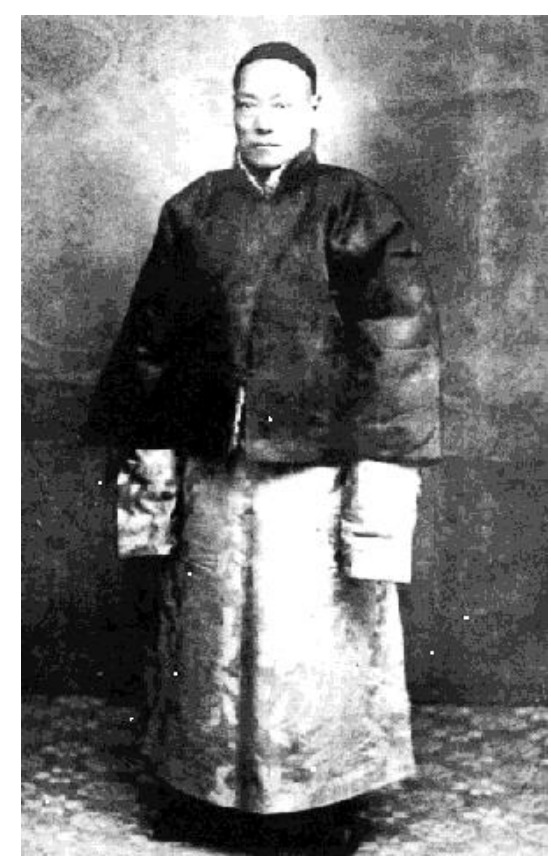

Fig. 1. Portrait of Yun Yu-ding (1862-1917)

\section{THE ACADEMIC TRANSFORMATION OF YUN YU-DING}

Before proceeding to discuss Yun's thoughts, it is important to offer a more detailed account of the man and his life. This account is compiled mainly from the records of an epitaph written by a Qing loyalist named Cao Yun-Yuan 曹 允源 (1855-1927) [2]. Through reading this epitaph, Yun was no different from the many previous generations of Chinese official scholars who had lived in late imperial China. Like them, he spent much of his life preparing for the civil service examinations and spent a good deal of effort reading and studying ancient texts. The biography of Yun can be divided into three time periods: firstly, Yun's experiences before taking the civil service examinations, then his life as a 
government official, and finally his time during the Republican China period after the 1911 Revolution.

\section{A. Early Intellectual Background (1862-1889)}

The dominant school of the Qing Dynasty had been the Han Learning of Evidential Study 汉学考据. This was an attempt based on philological methods to strip away the accretions of later exegesis and determine exactly what the classics had really meant. ${ }^{2}$ Yun could not help but be deeply influenced by evidential study as a young man, and he was a leading Confucian scholar in his home town of Yanghu 阳湖 (modern Jiangsu 江苏). At that time, Yun had a special veneration for the two most renowned Eastern Han (25-220AD) scholars: Zheng Xuan 郑玄 (127-200), the greatest exegete of classical texts, and $\mathrm{Xu}$ Shen 许慎 (58-147), the man who wrote China's first etymological dictionary Shuowen Jiezi 说文解字; an invaluable tool for understanding the meanings of words found in ancient books. It is generally accepted that Han Learning emphasised the careful accumulation of data and the use of inductive reasoning to arrive at the original meaning of the ancient texts. Thus, Yun was cautious not to read too widely without any particular focus. In his diary we find typical Han Learning criticism of Neo-Confucianist Song Learning 宋学, namely, that the metaphysical concerns of that age obscured many of the basic ideals of Confucianism and caused scholars to avail themselves of Buddhist concepts that had nothing to do with the original philosophy.[3] Yun was very proud that the Han Learning scholars in his era had a much better understanding of ancient classical texts, and even many aspects of Chinese history, than anyone before the beginning of the Qing dynasty.

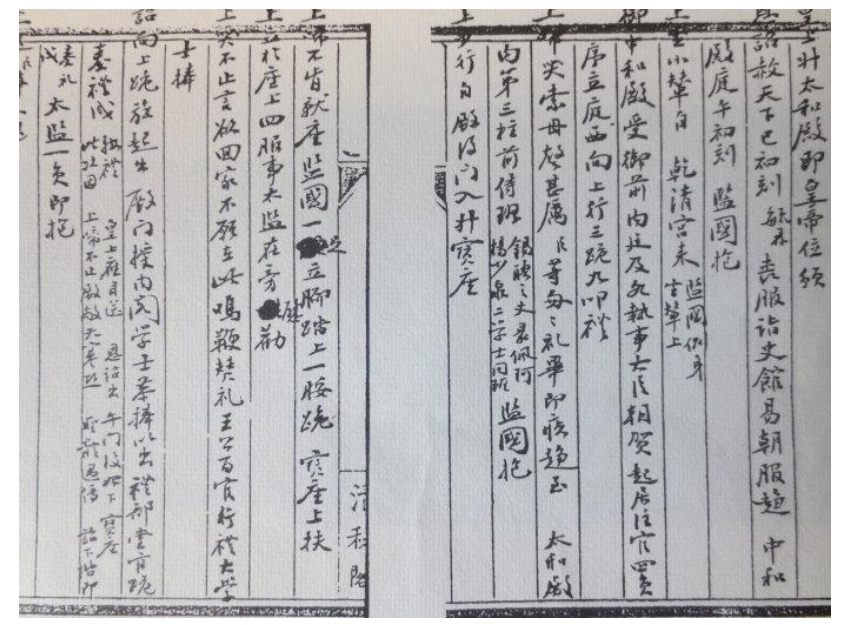

Fig. 2. The Manuscript of Cheng Zhai Diary.

In 1882, Yun went to Beijing to take the civil service examinations. At that time, they were mainly organised by a

\footnotetext{
${ }^{2}$ The Han Learning had come into being in the late seventeenth century, which was a reaction against the so-called "Song Learning", or Neo-Confucianism, which had arisen during the Song dynasty (12th century) This school of learning came to be called "Han Learning" because it sought out Han dynasty commentaries as being closer to the original texts. The most complete study of the Han Learning in a Western language is Elman, Benjamin A. From Philosophy to Philology: Intellectual and Social Aspects of Change in Late Imperial China, Cambridge, Mass.: Council on East Asian Studies, Harvard University, 1984.
}

high-ranking official named Wang Ming-Luan 汪鸣銮 (1839-1907), who was also an admirer of Qian-Jia text-critical research 乾嘉考据学 [4]. Through the Cheng Zhai Diary, we find that a number of disciples visited Wang Ming-luan before they attended the civil service examinations in order to cater to his academic preferences. During their visit the disciples showed Wang their work on evidential studies, Yun Yu-ding was among them. [5] The work he gave to Wang was called "A study on the six writing styles”六书转注明疏. This implies that he had already done a great deal of research in the study of ancient lexicography, which was itself a branch of evidential study.

\section{B. A Turn to Neo-confucianism (1889-1911)}

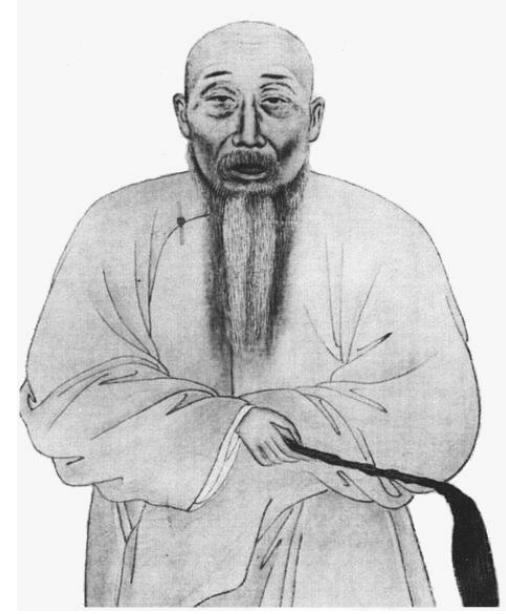

Fig. 3. Portrait of Xu Tong ( 1819-1900), a Chinese Confucian scholar and imperial tutor.

Although Wang Ming-Luan, chief examiner of the imperial civil service examinations, admired Han Learning, there was another important trend of thought in the Beijing academic community which was advocated by high-ranking officials such as Wo Ren 倭仁 (1804-1871), Xu Tong 徐桐 (1819-1900), Sun Jia-Nai 孙家勇 (1827-1909) and Wen Tong-He 翁同敛 (1830-1904) [6], all of whom adhered to the Song Learning of Neo-Confucianism and who all cherished moral cultivation. Although the Neo-Confucians had fallen out of favour during the Qing dynasty and were looked down upon by many followers of the Han Learning which had been so popular in China during the eighteenth century, the Late Qing dynasty saw a resurgence of interest in them. ${ }^{3}$ This has much to do with the academic preferences of those aforementioned high-ranking officials. ${ }^{4}$

\footnotetext{
${ }^{3}$ That the rise of Neo-Confucianism was one sign of a significant change in orientation sometime during the late Qing has been accepted as an incontrovertible fact by most historians. For the general study of the revival of neo-Confucianism in the late Qing, see, Shi Gexin 史革新, Qing Dai Lixue Shi清代理学史, Guangzhou: Guangdong Education Publishing House, 2007, ch.5. For the case study, see for example, Fan-sen Wang王汎 森, “Fang Dongshu and the Academic Atmosphere in Late Qing” 方东树与 晚清学风, Genealogy of Modern Chinese Thought, Taipei: Linking Publishing Company, 2003; Zhang Ruilong 张瑞龙, “The Tianli Sect Incident and the Transformation of Cultural Policy in the Mid-Qing: Research Concentrating on the Jiaqing Period", Bulletin of the Institute of Modern History Academia Sinica, vol. 71, pp. 51-87, 2011.

${ }^{4}$ On the definition of official-scholar, see Joanna F. Handlin, "In China, the official was also a scholar; he was both practical administrator, and moral leader. He drew inspiration from Confucius, who saw moral perfection, the
} 
Yun had great success in the imperial civil service examinations and became a jinshi in 1889. Upon his qualification as jinshi, he was nominated for entry into the Hanlin Academy, along with twenty two other successful candidates. He then studied and worked under Xu Tong, who was in charge of academy.

Once there, $\mathrm{Xu}$ Tong's introduction to the Song thinkers had a powerful impact on Yun Yu-ding. He became familiar with the philosophy of Zhu Xi 朱喜 (1130-1200) and increasingly found that he needed to closely match Xu's academic preferences if he was to gain any recognition. In 1889, he began to read Zhu $\mathrm{Xi}$ and Wang Yang-ming's writings. He also started to befriend other Neo-Confucian scholars, such as Mongolian Confucian scholar Yu Shi 豫师 (1852-1906) [7]. In his old age, he wrote Hanxue Shangdui Zhuiyan 汉学商兑赘言, a book which redirected scholars in the Late Qing to Zhu Xi's doctrines of learning. In the book, he also advocates unity between the knowledge and action (zhixingheyi 知行合一) espoused by the great Ming thinker Wang Yang-ming 王阳明 (1472-1529). Yun also had frequent interaction with Sun Jia-nai, another superior officer to him in both the political and scholarly fields. [8]

Through the Chen Zhai Diary, we find that Beijing was a diverse and open place for learning, where different scholars could easily form groups and pursue different paradigms. In addition, students at the Hanlin Academy often tried to pursue official careers and scholarly development at the same time. This helps us to understand how, due to real-life considerations, some of the scholars like Yun turned to Song Learning. At this point, Yun finally became an advocate of merging the teachings of the Zhu Xi and Wang Yang-ming schools. One year later, he was promoted and appointed to the Hanlin Academy as a complier 翰林院编修. This largely came about because of his close relationships in Beijing academic circles with Xu Tong and Sun Jia-nai. After that, he had a fairly successful official career, he was appointed as a scholar of the royal academy, a master editor of the national archives 国史馆协修及总纂，a royal court recorder，a scholar of the Hanlin Academy 翰林院侍读学士, and as an executive official of the royal academy 讲习馆总办. In 1910 , the Hanlin Academy established the Constitutionalism Institution 宪政研究所 and elected Yun as an executive for the New Deal and Constitutionalism Movement 新政立宪运动.

At the age of thirty eight, he completed his Han Studies scholarship and planned to spend the rest of his life studying Song Learning. He had even decided on a name for the book he intended to write, Zhengxiu Yaolu 正修要录, showing that he had paid a lot of attention to cultivating his moral character. For some reason however, he seems to have never started this project as no fragments of this work can be found.

With the start of the Late Qing reform in the early

cultivation of the gentleman, as the key to social harmony. In particular, the scholar-official drew support from the classic, The Great Learning, whose statement, 'Their hearts being rectified $\cdots$ their states were rightly governed,' affirmed that successful government and moral self-improvement were interdependent." Joanna F. Handlin, Action in Late Ming Thought: The Reorientation of Lü K'un and Other Scholar-Officials, University of California Press, Berkeley, 1983, p. 17. twentieth century, officials gradually realised and admitted that they were unqualified to handle the newly emerging political, economic, and diplomatic affairs of the country and started to study new Western ways of thinking. Yun however, refused. He believed that Western concepts would change from time to time, while the immortal principle ( $l i$, 理one concept of Neo-Confucianism) would remain unchanged. He pointed out that the great Song thinker, Zhu Xi, had been so good at administrating the country that specialising in studying the works of Zhu Xi was enough. [9]

\section{YUN's CRITIQUES ABOUT HAN-SONG CONTROVERSY}

Since Han Learning was the dominant school in the academic community during the Qing dynasty, Han Learning scholars tended to despise the Song Neo-Confucians for their textual misreading as well as for their excessive moralising. Throughout the Qing dynasty, there were scholars of Han Learning who continually attacked $\mathrm{Zhu} \mathrm{Xi}$ and the other Song thinkers, because they relied heavily on Han dynasty exegesis, which was after all, closer in time to when the classics were written. Han Learning was thus opposed to Song Learning. [10]

However, Han studies began to gradually be challenged by the intelligentsia during the Daoguang 道光 (1821-1850) and Tongzhi 同治 (1861-1875) reigns. The evidential studies sparked many radical critiques, such as whether Han Learning had any real usefulness in society. The intellectuals in effect asked, if Han Learning was totally correct, why did the dynasty survive the unparalleled crisis? And if Han Learning was good, why was the dynastic government not changing for the better? The Han Learning scholars never gave any positive answers to these critiques.

Based upon the degree of involvement of Neo-Confucianism, Yun Yu-ding criticised Dai Zhen 戴震 (1724-1777), a specialist in phonetics and the seal script but who often challenged Neo-Confucianist scholars on minor points, on the grounds that his ideas were too narrow and restricted. Chen Li 陈醴 (1810-1882) was one of the most important advocates for the reconciliation of the Han and Song approaches to studying the classics in the Late Qing period. In contrast to Dai Zhen, Yun praised him for his attempt to combine Song and Han Learning into a new synthesis, and for not despising the Song scholars despite being a leading Confucian of evidential studies.

Yun was living in an age of a declining economy and of devastating disorder. While tracing the origin of decline, like the scholars mentioned above, Yun blamed all of this on the prevailing of Han Learning. He disapproved of some Han Learning scholars who were mostly engaged in careful scholarship of ancient texts, for ignoring moral cultivation and the current political situation. He also drew an analogy with Han Learning and Mohism 墨学, whose democratic theories had been refuted by Menciu, who dismissed Mozi's 墨子 notion of “universal love" (jian'ai 兼爱) as a "denial of the father." (wufu wujun 无父无君) [11] Simply put, in Yun's diary we find the typical criticisms of Han Learning in the Late Qing era by Song scholars. 


\section{LIANG QI-CHAO'S APPRECIATION OF THE TAI ZHOU SCHOOL AND HIS INFLUENCE ON YUN}

Except for $\mathrm{Xu}$ Tong and Sun Jia-nai in the Beijing intellectual community, the next important influence on the development of Yun Yu-ding's philosophy came from Liang Qi-chao 梁启超 (1873-1929), a Chinese reformer who considered translating Western ideas and knowledge as an effective means to "renovate the people" and transform Chinese society and culture. He is also arguably one of the most seminal thinkers and widely read writers in modern Chinese history.

After 1903, Liang moved from advocating new morality to emphasising the traditional doctrine of the Yang-Ming School. On the one hand, this shift was influenced by the Japanese Yang-Ming doctrine 日本阳明学 and the yamato damash (the Japanese spirit) during his exile in Japan from 1898 to 1912 . To Liang, Confucian morality would help the Chinese people just as it did for the Japanese in Meiji Japan. On the other hand, he was pained by the realisation that very few people cared about reform. The cause of such conditions, he suggested, had to do with peoples' selfishness. Individual selfishness subsequently led to various social and national problems. He planned to use the Yang-Ming School to mould the new citizenry [12].

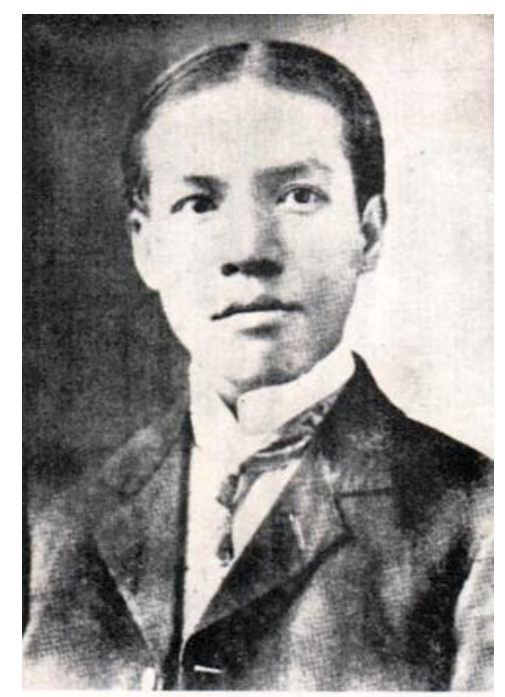

Fig. 4. Portrait of Liang Qichao (1873-1929), a Chinese scholar, journalist, philosopher and reformist during the Qing dynasty.

In 1905, Liang published his Abridgement of the Cases of Learning of Ming Confucians 节本明儒学案, in which he greatly appreciated the Tai Zhou School 泰州学派 and the Dong-lin Party 东林党 (a group of Confucian scholar-bureaucrats). Thus, he became the first intellectual since the Early Qing dynasty to cast a positive light on the Taizhou branch of the Yang-Ming School as well as the Dong-lin partisans. The Dong-lin movement was bitterly criticised for being deeply involved in factional politics, [13] and their discussions concerning government affairs as well as their lecturing and preaching to large audiences had been strictly banned by the Qing court. [14] In addition, members of the Taizhou School were often labelled as "wild Buddhists" ( kuangchan 狂禅) and Confucian scholars since the Late Ming period criticised them for promoting a skewed morality that contained many Buddhist elements.

In 1906, almost immediately after reading Liang's Abridgement of the Cases of Learning of Ming Confucians, [15] Yun became an adherent to the Tai Zhou School. It seems quite obvious that Yun's academic view of the Tai Zhou School went through some serious alterations. Ten years earlier, in 1896, he had bitterly criticised Wang Ji 王畿 (1498-1583), a typical figure from Tai Zhou School. Yun also agreed with the academic stance of Gu Xian-cheng 顾宪 成 (1550-1612), the leader of the Dong-lin Party, for his involvement in political affairs. For the next few years, Liang's work was very much on Yun's mind.

The high point of Liang's direct influence on Yun was reached during 1910, when he formed a group of officials, turning $\mathrm{Gu}$ Xian-cheng even more into a representative of political ethics. They tried to restore a Late Ming Qing-yi tradition 清议 by the way in which they associated with each other to criticise the government and encourage a change in ethics. [16]

Yun was a traditional scholar of the Late Qing period, who saw the decline of the dynasty. But he rejected the new reforms promoted by the imperial court, in particular its political and academic prospects regarding tradition and modernity. However, it is wrong to conclude that he had neither the energy nor the courage to present new ideas to the throne or adopt major reforms. In investigating his "intellectual source", we find that his transformation in his evaluation of the Ming era has much to do with the reformer Liang Qi-chao. He was deeply influenced by the traditional academic argument advocated by Liang. It shows him to be an independent Confucian scholar who attempted to maintain individual thoughts and standpoints at the height of the influence of Western ideas.

\section{CONCLUSION}

This study focused on the Cheng Zhai Diary by Yun Yu-ding in order to investigate his views on Qing scholarship. Despite a lifelong dedication to Neo-Confucianism, Yun was not an advocate of it at the very beginning; in the early stages of his studies he started with the evidential. The study then analysed the reasons for his academic switch towards the Neo-Confucianism. Influenced by his master and teacher, $\mathrm{Xu}$ Tong, Yun became an advocate of Neo-Confucianism. Meanwhile, Yun's academic view of Neo-Confucianism changed from the Cheng-Zhu School to the Tai Zhou branch of the Yang-Ming School.

To conclude, the prevailing academic findings often take revolutionaries' writings such as Zhang Tai-Yan 章太炎 (1869-1936), Liang Qi-Chao, Liu Shi-Pei 刘师培 (1884-1919) as the academic foundation of the Late Qing dynasty, [17] with little concern for other characters in the same time period, especially other official elites in the Qing government. This paper intends to offer a balance to the excessive attention paid to the scholarship and thoughts of reformers and revolutionaries in the Late Qing period.

In the resurgence of Neo-Confucianism, scholars have already done a great deal of research. It is widely accepted that Neo-Confucianism earned reappraisal among intellectual 
circles as a result of the increasing crisis during the Dao-guang and Tong-zhi reigns, because of Han Learning ignoring matters of principle and government affairs. However, there still exist special cases and details yet to be discovered. In the case discussed in this essay, Yun turned to Neo-Confucianism because of real-life considerations. He wanted to cater to his master and superior official who offered advantages to him in the political and scholarly fields. This is different from the reasons previously discussed for the rise of Neo-Confucianism in the Late Qing period. Therefore, in the framework of the academic and ideological history of the Late Qing dynasty, further research into Yun Yu-ding as a scholar and an official would be of great importance.

\section{REFERENCES}

[1] Z. H. Lin, "Analysis of Yun Yu-ding's diary: The political identity of Qing loyalists," Journal of Cross-Strait Studies, vol. 2, pp. 229-246, 2006.

[2] X. X. Bian, Xinhai Renwu Beizhuanji, Beijing: Unity Press, 1991, pp. 738-740.

[3] Y. D. Yun, Cheng Zhai Diary, Hangzhou: Guji Chubanshe, 2004, p. 7 , $14,18,31,38-39$.

[4] Draft History of Qing, Beijing: Zhonghua Book Company, 1977, vol. 30, p. 12429.

[5] Cheng Zhai Diary, pp. 18, 21-22.

[6] X. M. Qi, "Wen Tonghe's academic preference and his influence on late qing scholarship," Journal of Modern Chinese History, vol.11, pp. 21-40, 2014

[7] Cheng Zhai Diary, pp. 74-79.

[8] Cheng Zhai Diary, p. 462.

[9] Cheng Zhai Diary, pp. 161-163.

[10] Y. S. Yu, "Some preliminary observations on the rise of ch'ing confucian intellectualism," Tsing-hua Journal of Chinese Studies, 10.1-2. 1975, pp. 105-136.

[11] Cheng Zhai Diary, p. 120, 164, 189.

[12] P. Zarrow, After Empire: The Conceptual Transformation of the Chinese State, 1885-1924, Stanford University Press, 2012, ch. 2; Chang, Hao. Liang Ch'i-Ch'ao and Intellectual Transition in China, London: Oxford University Press, 1971; Huang Ko-wu, "Liang Qichao and the Confucian Tradition: An Investigation Based on Wang Yang-ming in late Qing Dynasty", History Teaching, vol. 3, 2004; Lynn Struve, "Modern China's Liberal Muse: The Late Ming," Ming Studies, vol.63, pp. 38-68, 2011.

[13] For information on factionalism in the late Ming, see Charles O. Hucker, "The Tung-lin movement of the late Ming period," in John
King Fairbank, Chinese Thought and Institutions, University of Chicago Press, 1957, pp. 132-163; Ono Kazuko, The Dong-lin movement and the Restoration Society in the late Ming, Shanghai: Shanghai Ancient Books Publishing House, 2006.

[14] The veritable of the Qing dynasty, Beijing: Zhonghua Book Company, 1985, no. 14, vol. 1055 , p. 99.

[15] C. Hung-Lam, "Liang Qichao and his abridgement of the cases of learning of Ming confucians," Chinese Culture, No.35, 2012.

[16] Cheng Zhai Diary, pp. 445-447.

[17] W. Fan-Sen, Chang T'ai-yen and His World, Taipei: China Times Publishing Company, 1985; Ko-wu Huang, "Liang Qichao and Immanuel Kant", in Joshua A. Fogel, The Role of Japan in Liang Qichao's Introduction of Modern Western Civilization to China, University of California: Berkeley: Institute of East Asian Studies, 2004, pp. 125-155; Qian Mu, History of Chinese scholarship of the past three hundred years, Shanghai: Shangwu, 1937.

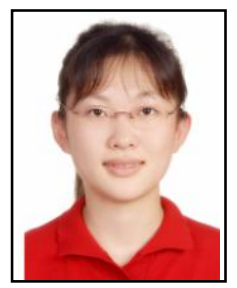

Liu Xunqian is currently a Ph.D. candidate in the School of Chinese at the University of Hong Kong. She received her B.A. and M.A. in Chinese history from Tsinghua University, with the honor of outstanding graduate student in Beijing. Her research directions are focusing on history of later imperial China with special interests in the intellectual and political aspects of the Ming dynasty. She is a holder of Postgraduate Scholarship (PGS) in Hong Kong.

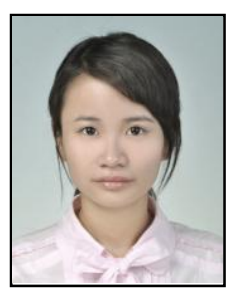

Yang Yi is currently a doctoral candidate in the School of Chinese, the University of Hong Kong. She joined the school in 2014 as an awardee of the Hong Kong PhD Fellowship Scheme. She obtained her BA, MA from the Tongji University and the National University of Singapore separately. Her research interest is modern Chinese popular literature and cultural history. Her current project is what happened to the Western import of detective fiction in modern china, including how was it explained, transformed and localized during that time. And how did the Chinese national culture imagine and interpret its own moment of unfolding.

Miss Yang Yi has published several essays in Chinese academic journals, also won the National Scholarship in China and the 15th Singapore Tertiary Chinese Literature Awards. She is a recipient of the Hong Kong PhD Fellowship. 